\title{
Analysis and Optimization of Stamping B-pillar of High Strength Steel DH780
}

\author{
Wenyu Ma*, Jianwei Yang, Jun Zhang, Xuebin Zheng and Baochuan Wang \\ Research Institute of Technology of Shougang Group Co., Ltd., China \\ Beijing Key Laboratory of Green Recycling Process for Iron \& Steel Production Technology, China \\ Beijing Engineering Research Center of Energy Steel, China \\ ${ }^{*}$ Corresponding author
}

\begin{abstract}
In this study, the high strength steel DH780 produced by Shougang Group was used to form a traditional part B-pillar. The effect of process parameters, namely blank holder force and friction coefficient on the formability was analyzed. The decrease of BHF and friction coefficient can increase the formability. And the optimization methods were introduced and applied to form a qualified part. Three optimization methods were employed, namely optimizing the critical surface of die, modifying the geometric parameter of drawbead, and changing the corner size near the critical area. The qualified part can be formed with the proper optimization.
\end{abstract}

Keywords-high strength steel; B-pillar; blank holder force; optimization

\section{INTRODUCTION}

The high strength steel is a popular material used in the automotive vehicles. DH series steel is a good material with reasonable price and high quality. Recently the high strength steel got much attention and many researchers devoted the effort to the application of high strength steel [1, 2].Chongthairungruang et al.[3] studied the springback behavior of high strength dual phase steel, and an S-shaped U-channel part was used. The FE simulation method and experiments were employed to the formability behavior of high strength steel.Sumikawa et al. [4] researched the DP steel using experiment method. The stress-strain relationship was researched in the biaxial tension-compression deformation procedure.

The optimization method is used to form a qualified part. Generally, the optimization methods are blank size optimization, process parameter optimization, die optimization and so on.Shi et al. [5] proposed a method to optimize the die shape in sheet metal forming procedure. The optimization was used to improve the stamping quality to decrease the rupture, wrinkles and surface defects.

In this study, the DH780 steel is used to form a B-pillar. The effect of process parameters on the formability of B-pillar is analyzed and the optimization methods for diesare employed to get a qualified part.

\section{FE MODEL}

The material used in this study is DH780, and the yield stress is $518 \mathrm{MPa}$, tensile stress is $809.6 \mathrm{MPa}$, elongation is $16.9 \%, r$ is 0.75 and $n$ is 0.16 , which were set in the FE software.

According to the real part, the FE model was established in the FE software.

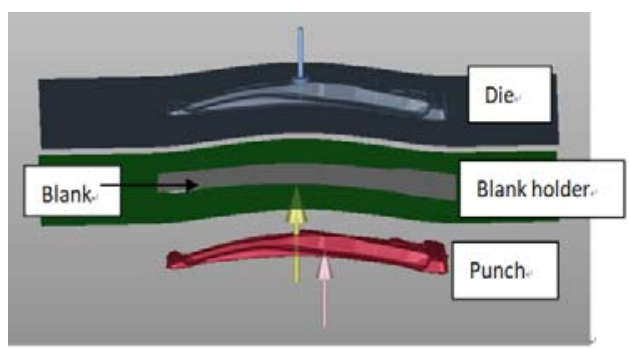

FIGURE I. FE MODEL FOR STAMPING

The FE model has 4 parts, namely die, blank holder, punch, blank. The outline of the blank is given in the following figure The outline of blank is designed in detail in order to form a qualified part and save the material. The outline of blank is shown in follows.

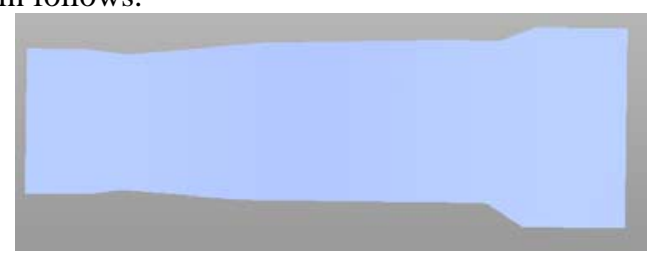

FIGURE II. OUTLINE OF BLANK

\section{THE SimUlation RESUltS AND OPTIMIZATION}

\section{A. The Effect of Process Parameters on the Formability}

Firstly, several values of blank holder force and friction coefficient were used to test the formability of this part using DH780. The simulation results are listed in the following table. It can be seen from the table that the crack happens for these conditions. The drawbead and die surface are not changed. 
TABLE I. PROCESS PARAMETER ARRANGEMENT AND SIMULATION RESULTS

\begin{tabular}{ccccc}
\hline No. & Material & BHF(kN) & Friction coefficient & Simulation results \\
\hline $\mathbf{1}$ & DH780 & 2000 & 0.15 & Crack in corner \\
$\mathbf{2}$ & DH780 & 1000 & 0.15 & Slight crack in corner \\
$\mathbf{3}$ & DH780 & 1000 & 0.1 & Slight crack in corner \\
$\mathbf{4}$ & DH780 & 500 & 0.1 & Slight crack in corner, thickening in flange \\
\hline
\end{tabular}

1) The blank holder force is $3000 \mathrm{kN}$, friction coefficient is 0.15 . Under this condition, the serious crack happens in the sidewall. The simulation result is shown in the following figure.

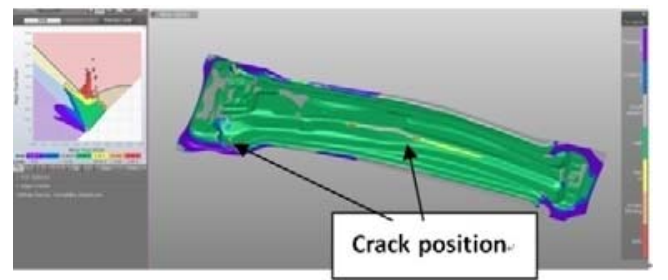

FIGURE III. THE SIMULATED RESULT OF FLD AND CRACK POSITION FOR BHF OF 3000 KN AND FRICTION COEFFICIENT OF 0.15 .

2) The blank holder force is $1000 \mathrm{kN}$, friction coefficient is 0.15 . Under this condition, the slight crack happens near the corner. The corresponding simulation result is given in the following figure

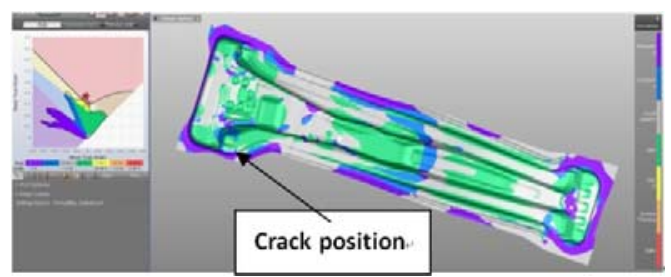

FIGURE IV. THE SIMULATED RESULT OF FLD AND CRACK POSITION FOR BHF OF 1000 KN AND FRICTION COEFFICIENT OF 0.15 .

\section{B. Die Modification Optimization for DH780}

Three die modification optimization methods were applied. The method one is optimizing the danger area. The second method is changing the drawbead near the crack area. The third method is changing the corner geometrical dimensions near the crack area.

a) Optimization method 1: Die surface modification for critical area

According to the simulation results, the corner of the part has a bad formability, and it is hard to improve it by changing the process parameter values, namely BHF and friction coefficient. So, other optimization method can be tried, for example changing geometry size of danger area. Generally, the large corner size can improve the formability.

The FE software has the ability to modify the corner, and the software can calculate the size automatically after choosing the selected area for optimization. The green area is selected and shown in the following figure. After smoothing the green area, the formability can be improved.

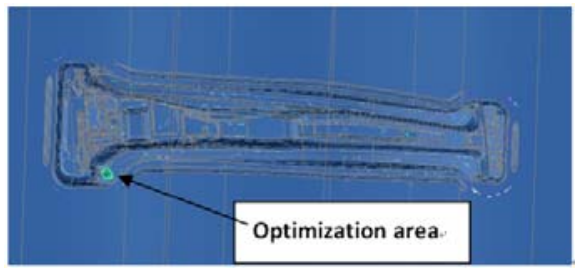

FIGURE V. OPTIMIZATION AREA FOR THE PART

TABLE II. THE TEST DESIGN AND SIMULATION RESULTS AFTER OPTIMIZATION

\begin{tabular}{ccccc}
\hline No. & Material & $\begin{array}{c}\text { BHF } \\
\mathbf{( k N )}\end{array}$ & $\begin{array}{c}\text { Friction } \\
\text { coefficient }\end{array}$ & $\begin{array}{c}\text { Simulation } \\
\text { results }\end{array}$ \\
\hline $\mathbf{1}$ & DH780 & 1000 & 0.1 & Good \\
$\mathbf{2}$ & DH780 & 2000 & 0.1 & Good \\
$\mathbf{3}$ & DH780 & 2000 & 0.15 & Slight crack in corner \\
$\mathbf{4}$ & DH780 & 1500 & 0.15 & Slight crack in corner \\
$\mathbf{5}$ & DH780 & 1000 & 0.15 & Good
\end{tabular}

It can be seen from the table that the formability becomes better, and the qualified part can be achieved. The BHF can be set as $1000 \mathrm{kN}$, friction coefficient 0.15 . The BHF and friction coefficient can also be set as $1500 \mathrm{kN}$ and 0.1 . Some simulation results are given in the follows.

(1) The process parameters are set as follows: BHF 2000 $\mathrm{kN}$, friction coefficient 0.1 . After simulation, the formability is good. And the crack is avoided.

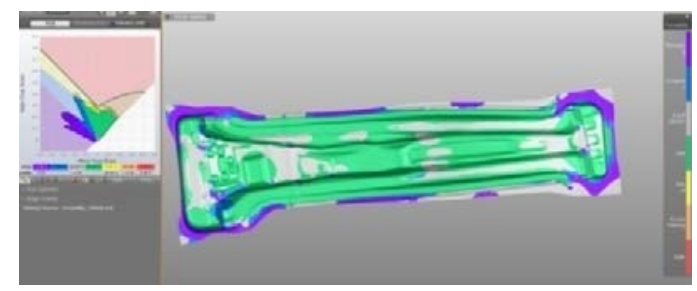

FIGURE VI. SIMULATION RESULT AND FLD DIAGRAM WITH BHF OF 2000 KN, AND FRICTION COEFFICIENT OF 0.1.

(2) The process parameters are set as follows: BHF 1000 $\mathrm{kN}$, friction coefficient 0.15 . The part in the simulation result is also qualified without crack.

b) Optimization method two: draw bead optimization near the critical area 


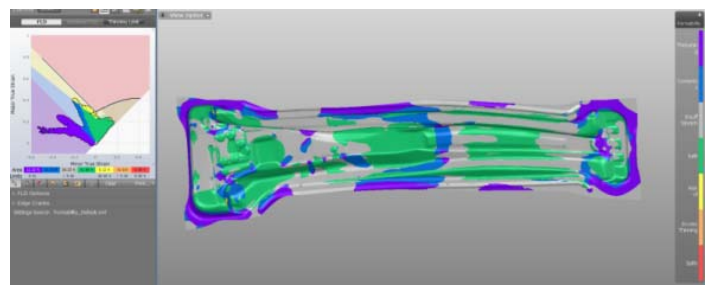

FIGURE VII. SIMULATION RESULT AND FLD DIAGRAM WITH BHF OF $1000 \mathrm{KN}$, AND FRICTION COEFFICIENT OF 0.15 .

The optimization for the drawbead can be used to decrease the crack probability. After modifying the drawbead, the simulations were conducted. The drawbeads were changed as follows in the figure. The left drawbead was deleted. The low drawbeadis shortened and the drawbead dimension is changed to $5 \mathrm{~mm}$ height and $2 \mathrm{~mm}$ width.

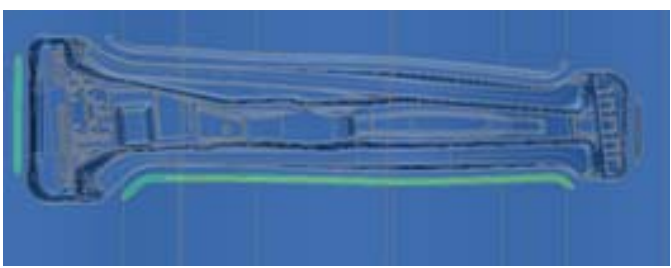

FIGURE VIII. OPTIMIZATION DIAGRAM FOR THE DRAWBEAD

TABLE III. SIMULATION ARRANGEMENT AND RESULTS AFTER DRAWBEAD OPTIMIZATION

\begin{tabular}{clccc}
\hline No. & Material & BHF(kN) & Friction coefficient & Simulation results \\
\hline $\mathbf{1}$ & DH780 & 1000 & 0.13 & Slight crack in corner \\
$\mathbf{2}$ & DH780 & 1000 & 0.1 & Good \\
\hline
\end{tabular}

The simulation result diagram for BHF of $1000 \mathrm{kN}$ and friction coefficient of 0.1 is shown in the following figure. By changing the drawbead dimension, the crack can be avoided.

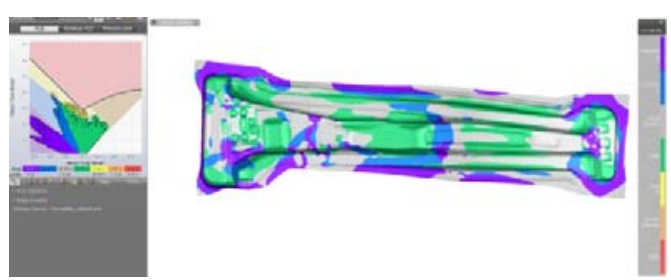

FIGURE IX. THE SIMULATION RESULT AND FLD DIAGRAM AFTER DRAWBEAD OPTIMIZATION

TABLE IV. THE TEST DESIGN AND SIMULATION RESULTS AFTER OPTIMIZATION FOR CORNER SIDE

\begin{tabular}{ccccc}
\hline No. & Material & BHF(kN) & Friction coefficient & Simulation results \\
\hline $\mathbf{1}$ & DH780 & 1000 & 0.15 & Good \\
$\mathbf{2}$ & DH780 & 1100 & 0.15 & Crack in both sides \\
$\mathbf{3}$ & DH780 & 1200 & 0.15 & Good both sides \\
$\mathbf{4}$ & DH780 & 1200 & 0.13 & Good \\
$\mathbf{5}$ & DH780 & 1300 & 0.13 & Slight crack \\
$\mathbf{6}$ & DH780 & 1400 & 0.13 & Crack \\
$\mathbf{7}$ & DH780 & 1500 & 0.13 & Slight \\
$\mathbf{8}$ & DH780 & 1500 & 0.1 & Slight \\
\hline $\mathbf{9}$ & DH780 & 1400 & 0.1 & Slight \\
\hline
\end{tabular}

After modifying the corner size near danger area, the formability can be improved to get a qualified part. It can be seen from the simulation results that the good process parameters are BHF of $1000 \mathrm{kN}$ and friction coefficient of 0.15 ; $\mathrm{BHF}$ of $1300 \mathrm{kN}$ and friction coefficient of 0.13 .

c) Optimization method 3: Optimization for the corner size near critical area

Optimizing the corner size near critical area can improve the formability of the part to avoid the crack.

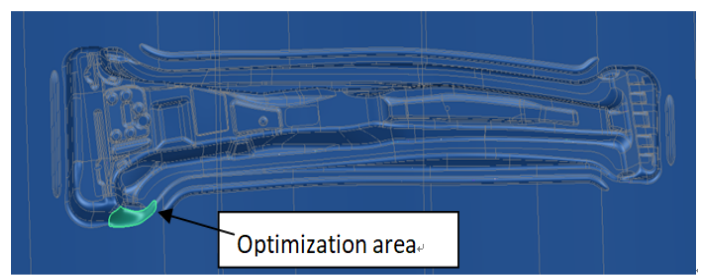

FIGURE X. THE OPTIMIZATION DIAGRAM FOR THE CORNER SIDE 
advice for process parameter arrangement is BHF of $1000 \mathrm{kN}$ and friction coefficient of 0.15 or BHF of $1500 \mathrm{kN}$ and friction coefficient of 0.1 .

3) Through modifying the drawbead size, the crack can be avoided. The BHF is proposed as $1000 \mathrm{kN}$, and friction coefficient is proposed as 0.1 .

4) After corner size optimization, the formability can be improved to avoid the crack. The BHF can be set as $1000 \mathrm{kN}$, and friction coefficient can be set as 0.15 . At the same time, the BHF can be set as $1300 \mathrm{kN}$ and friction coefficient can be set as 0.13 .

\section{ACKNOWLEDGMENT}

The authors would thank Professor Jianguo Lin very much, from Royal Academy of Engineering UK, for the warm help and guideline.

\section{REFERENCES}

[1] Wang J, A.S.G.M., Flexural behaviour of hot-finished high strength steel square and rectangular hollow sections. Journal of Constructional Steel Research, 2016. 121: p. 97-109.

[2] A. Ghaei, D.E.G.B., Springback simulation of advanced high strength steels considering nonlinear elastic unloading-reloading behavior. Materials and Design, 2015. 88: p. 461-470.

[3] B. Chongthairungruang, V.U.S.S., Experimental and numerical investigation of springback effect for advanced high strength dual phase steel. Materials and Design, 2012. 39: p. 318-328.

[4] S. Sumikawa, A.I.J.H., Improvement of springback prediction accuracy by considering nonlinear elastoplastic behavior after stress reversal. Journal of Materials Processing Technology, 2017. 241: p. 46-53.

[5] Xiaoxiang Shi, J.C.Y.P., A new approach of die shape optimization for sheet metal forming processes. Journal of Materials Processing Technology, 2004. 152: p. 35-42. 